\title{
PROCESSOS DE INCLUSÃO E DOCÊNCIA COMPARTILHADA NO III CICLO $0^{1,2}$
}

\author{
Clarice Salete Traversini* \\ Maria Luisa Merino de Freitas Xavier** \\ Maria Bernadette Castro Rodrigues*** \\ Maria Isabel Habkcost Dalla Zen**** \\ Nádia Geisa Silveira de Souza*****
}

RESUMO: O artigo analisa a implementação do Projeto de Docência Compartilhada em duas escolas cicladas municipais de Porto Alegre/RS, destacando seus limites e possibilidades. O estudo inscreve-se na perspectiva dos Estudos Culturais, a partir das noções de diferença e inclusão, para pensar um currículo e propostas pedagógicas em que o outro seja visibilizado e posicionado como sujeito que aprende. O material empírico abrange registro de reuniões pedagógicas das referidas escolas, observações em salas de aula e análise de produção textual de alunos. A investigação possibilita constatar que o projeto em questão, embora em fase de implementação, apresenta-se produtivo no que tange: ao exercício compartilhado da docência nesta modalidade; à desnaturalização das diferenças entre os alunos; à concretização de aprendizagens cognitivas e sociais, buscando respeitar os tempos e as possibilidades desses alunos; e, ainda, à paulatina adequação do currículo às exigências desse projeto inclusivo.

Palavras-chave: Práticas de Inclusão. Docência Compartilhada. Constituição do sujeito Aluno. Práticas Curriculares.

\footnotetext{
* Doutora em Educação pela Universidade Federal do Rio Grande do Sul (UFRGS); Professora do Programa de Pós Graduação em Educação da Universidade Federal do Rio Grande do Sul (PPGEDU/UFRGS); Integrante do Grupo de Pesquisa sobre Educação e Disciplinamento (GPED) e do Núcleo de Estudos sobre Currículo, Cultura e Sociedade (NECCSO) da Universidade Federal do Rio Grande d Sul (UFRGS). E-mail: clarice.traversini@ufrgs.br

** Doutora e em Educação pela Universidade Federal do Rio Grande do Sul (UFRGS); Professora do Programa de Pós-Graduação da Universidade Federal do Rio Grande do Sul (PPGEDU/UFRGS); Coordenadora do Grupo de Pesquisa sobre Educação e Disciplinamento (GPED) e do Núcleo de Estudos sobre Currículo, Cultura e Sociedade (NECCSO- UFRGS). E-mail: E-mail: mlxavier@uol.com.br

** * Mestre em Educação pela Universidade Federal do Rio Grande do Sul (UFRGS); Coordenadora do curso de Pedagogia da Universidade Federal do Rio Grande do Sul (UFRGS) e Integrante do Grupo de Pesquisa sobre Educação e Disciplinamento da Universidade Federal do Rio Grande do Sul (GPED-UFRGS). E-mail: crodrigues@cpovo.net

**** Doutora em Educação pela Universidade Federal do Rio Grande do Sul (UFRGS); Professora do curso de Pedagogia e coordenadora do Estágio de Docência 6 a 10 anos (UFRGS); Integrante do Grupo de Pesquisa sobre Educação e Disciplinamento (GPED) e do Núcleo de Estudos sobre Currículo, Cultura e Sociedade da Universidade Federal do Rio Grande do Sul (NECCSO - UFRGS). E-mail: beladzen@terra.com.br

***** Doutora em Bioquímica/Educação em Ciências e licenciada em Biologia pela Universidade Federal do Rio Grande do Sul (UFRGS); Professora do Programa de Pós-Graduação em Educação (PPGEDU) e Programa de Pós-Graduação Educação em Ciências: Química da Vida e Saúde do Instituto de Ciências Básicas da Saúde da Universidade Federal do Rio Grande do Sul (PPGQVS/ICBS/UFRGS) e do Curso de Pedagogia. Pesquisa na área da Educação e da Educação em Ciências práticas implicadas na constituição do corpo; Integrante do Grupo de Pesquisa sobre Educação e Disciplinamento da Universidade Federal do Rio Grande do Sul (GPED- UFRGS). E-mail: nadiags@terra.com.br
} 


\section{PROCESSES PERTAINING TO INCLUSIVITY AND SHARED TEACHING IN THE THIRD TEACHING-CYCLE}

ABSTRACT: This paper analyzes the implementation of the Shared Teaching Project in two municipal schools in Porto Alegre/RS, emphasizing both its limitations and possibilities. The study takes a Cultural Studies perspective to deal with the notions of difference and inclusion, in order to come up with a curriculum, and associated pedagogical proposals, where "the other" is envisioned and conceptualized as a student who learns. The empirical data covers records of pedagogical meetings held in the respective schools, classroom observations, and an analysis of texts produced by the students. This investigation shows that, although still in its implementation stages, the project has already been productive with respect to the shared teaching exercises, carried out within this approach; homogenization of students; concretization of cognitive and social learning, while seeking to respect students' availability and abilities; and furthermore, appropriate curriculum achievement in order to meet the demands of this project, pertaining to inclusivity.

Keywords: Practices for Inclusivity. Shared Teaching. Constitution of the Student-Subject. Curriculum Practices.

\section{Introdução}

Este artigo é parte de investigações realizadas por um grupo de pesquisa $^{3}$ cujo foco de interesse atual vêm sendo as práticas curriculares implicadas na constituição de alunos ${ }^{4}$ incluídos nos anos finais do Ensino Fundamental (E. F.). Para tanto, examinamos, em escolas municipais de Porto Alegre/RS, processos de ensino-aprendizagem e socialização postos em funcionamento pelas políticas de inclusão adotadas nas últimas décadas no país. O estudo inscreve-se na perspectiva dos Estudos Culturais, a partir das noções de diferença e inclusão, para pensar um currículo e propostas pedagógicas em que o outro seja visibilizado e posicionado como sujeito que aprende.

O estudo em questão ocorreu em duas escolas municipais organizadas por Ciclos de Formação - aqui denominadas de escola $G$ e escola $\mathrm{M}$-, nas quais as políticas de inclusão vêm criando espaços para ingresso, atendimento e permanência de alunos habitualmente excluídos das escolas regulares, os quais, hoje, frequentam o III Ciclo do E. F.

Conforme Maria Luisa Xavier (2007), a organização da instituição escolar por Ciclos de Progressão Continuada vem sendo proposta por meio de políticas públicas, no país, desde a década de 1960, estando 
presente no ideário pedagógico nacional desde os anos 1920. Tiveram como referência o "sistema de avanços progressivos" adotado em escolas dos Estados Unidos e da Inglaterra. As escolas anglo-saxônicas, na visão de Elba Sá Barreto e Eleny Mitrulis (2004), caracterizavam-se por serem mais tolerantes em relação às diferenças de aprendizagem dos estudantes do que as escolas de tradição latina, das quais derivou nosso sistema educacional.

Conforme autores como Miguel Arroyo (1997; 1999), Creso Franco (2001; 2003), Luis Carlos de Freitas (2000; 2003) e Barreto e Mitrulis (2004), as propostas de organização da escola por ciclos relacionam-se à percepção de que a tradicional organização escolar seriada não tem conseguido "segurar" a população habitualmente excluída do sistema, os segmentos pertencentes às classes populares, os quais políticas de inclusão vêm tentando acolher face aos atuais processos de democratização.

Tal organização escolar compreende períodos de escolarização que ultrapassam as séries anuais, apresentam-se organizados em blocos cuja duração varia, podendo atingir até a totalidade de anos prevista para determinado nível de ensino. Apresenta-se com outra estrutura que vislumbra o fim da exclusão, da defasagem idade/turma, tão comuns na escola seriada. São propostas de redefinição dos tempos e dos espaços escolares, criando a possibilidade de respeitar, mas também de interferir nos ritmos e nos tempos de aprendizagem do estudante, visando a permitir, além do acesso e da permanência nas instituições escolares, o aproveitamento desejado em termos de socialização e aquisição de conhecimentos, minimizando a evasão e a repetência e regularizando o fluxo escolar. Nesse contexto, os conhecimentos e as habilidades seriam ampliados pela valorização e pelo entendimento das culturas locais. Nessa abordagem, a escola passa a ser vista como um polo cultural, isto é, como espaço articulador do contexto sociocultural da comunidade.

Esse tipo de organização, presente, atualmente, em muitas das administrações municipais e também em algumas estaduais, identificadas com um espectro político progressista existente desde a redemocratização do país, em meados dos anos 1980, permitiu que a proposta da escola por ciclos passasse a ser incorporada nos documentos legais, por meio, explicitamente, da LDBEN 9495/96.

Freitas (2003) e Arroyo (1999) chamam atenção sobre a necessária distinção a ser feita entre Ciclos de Progressão Continuada e Ciclos de 
Formação. Para Freitas (2003), tais proposições são fruto dos embates políticos dos anos 1990. Procuraram alterar os tempos e os espaços da escola, à medida que as propostas políticas neoliberais e progressistas foram adquirindo controle sobre o aparato estatal, reafirmando que tais propostas pedagógicas são provenientes de diferentes políticas e não podem ser examinadas como se fossem um conjunto homogêneo.

Ciclos de Progressão Continuada, na compreensão do autor, referem-se a experiências norteadas pela utopia liberal de uma escola eficaz para todos, onde a "inclusão" aparece como conceito central. Os Ciclos de Formação, por outro lado, reúnem experiências norteadas pela superação da utopia liberal, visando à superação dos objetivos restritos da escola liberal (aprendizagem de conteúdos escolares, usualmente Português e Matemática, por exemplo) e apontam para a incorporação de experiências socialmente significativas dos estudantes, visando a propiciar seu desenvolvimento crítico e social.

No ano de 1995, criou-se, em Porto Alegre/RS, por solicitação da comunidade nas reuniões do Orçamento Participativo ${ }^{5}$, uma escola onde se desenvolveu a primeira experiência de organização por Ciclos de Formação, gestada num trabalho coletivo do corpo docente com a participação da comunidade ${ }^{6}$. A escola tinha como desafio repensar o ensino por séries, até então a única forma de organização adotada ${ }^{7}$. A proposta foi organizada em três ciclos correspondentes às etapas de vida dos estudantes (infância, pré-adolescência e adolescência), visando a respeitar o ritmo, o tempo, as experiências e as características da faixa etária dos alunos, bem como dar continuidade às suas aprendizagens, nos três anos de cada ciclo. A organização dos dois Ciclos finais deu-se por áreas, com uma dimensão interdisciplinar, conforme especificado nas Bases Curriculares ${ }^{8}$. As Turmas de Progressão - agrupamentos de alunos com defasagem entre faixa etária e escolaridade - são definidas como espaços para abrigar estudantes com necessidade de atendimento especializado, visando a enturmá-los, assim que possível, nas turmas regulares do ano/ciclo. Nelas, devia-se, também, proceder à adaptação dos estudantes provenientes de outras escolas, assim como daqueles que não possuem escolaridade anterior, permitindo-lhes avançar para uma turma regular logo que apresentassem condições de continuar, adequadamente, sua socialização e seus estudos e, nos últimos tempos, abrigando também alunos oriundos de classes ou escolas especiais. 
As políticas de inclusão referidas determinam como público da Educação Especial alunos com deficiência, transtornos globais de desenvolvimento e altas habilidades/superdotação. Considera-se aluno com deficiência aquele que tem impedimentos de longo prazo, de natureza física, mental, intelectual ou sensorial, e que podem ter restringida sua participação na escola e na sociedade. Os alunos com transtornos globais do desenvolvimento apresentam alterações qualitativas das interações sociais recíprocas e na comunicação, um repertório de interesses e atividades restrito, estereotipado e repetitivo. Incluem-se aí alunos com autismo e psicose infantil (VASQUES, 2008). Alunos com altas habilidades/superdotação demonstram potencial elevado nas áreas intelectual, acadêmica, liderança, psicomotricidade e artes (BRASIL, 2008).

O presente estudo direciona-se, especificamente, a duas turmas do segundo ano do III Ciclo, em que se encontram alunos oriundos das chamadas Turmas de Progressão, que representaram, quando de sua criação, uma alternativa para lidar com as diferenças. Essa forma de enturmação, ao longo do tempo, terminou produzindo efeitos negativos na autoestima dos alunos, não favorecendo a aprendizagem. Trata-se de alunos com as chamadas "necessidades educativas ou educacionais especiais", NEE, especificamente com laudos de deficiência mental, transtorno global de desenvolvimento, entre outros.

A presença de tais alunos em turmas regulares foi o principal motivo que gerou o Projeto de Docência Compartilhada (D.C.), implementado, em 2008, em quatro escolas da rede. O projeto teve a intenção de inserir os alunos das TPs em turmas regulares, com atuação de mais de um professor, um especialista nas diferentes áreas de conhecimento e um pedagogo, na tentativa de promover aprendizagens pelo contato entre alunos ditos "normais" e "especiais", que se encontravam em momentos diferentes quanto à aquisição de conhecimentos escolarizados. Essa modalidade de ensino foi criada, então, como alternativa para valorizar a diversidade, enfrentar a cristalização das dificuldades e superar a segregação gerada pela enturmação nas TPs.

Para a criação dessa proposta inclusiva, as referidas escolas se apoiaram, especialmente, nos estudos de autores como Claudio Baptista (2006) e Hugo Beyer (2006), os quais defendem que para um grupo supostamente mais homogêneo de crianças pode ser suficiente um professor, mas que, numa classe inclusiva, é necessário um segundo profes- 
sor, considerando-se as características de tais alunos ${ }^{10}$. Tais autores defendem, também, a exigência de um número menor de estudantes em sala de aula, para permitir intervenções mais pontuais, contemplando as singularidades, aprendizagens prévias e diferentes tempos de cada um.

É importante destacar as condições favoráveis para tal empreendimento criadas pelas políticas internacionais e nacionais. No Brasil, a ideia de inclusão e de escola inclusiva surge a partir da influência internacional decorrente dos movimentos iniciados nos anos 1960. O desencadeador disso foi a Declaração Mundial de Educação para Todos, produzida em Jomtien, na Tailândia, em 1990, que propôs a chamada "Educação para Todos". Tal princípio foi aprofundado e divulgado com a Conferência Mundial de Educação Especial, em 1994, que aconteceu em Salamanca, na Espanha, e referendado em 2008. O documento, conhecido como Declaração de Salamanca, cujo paradigma é o da Educação Inclusiva, defende a inclusão de pessoas com necessidades educacionais especiais no sistema regular de ensino. Esses movimentos geraram legislações com a finalidade de assegurar o direito à educação de todos em um mesmo sistema.

Ressalta-se, aqui, que as políticas inclusivas, sob nosso entendimento, não se concretizam da mesma forma como foram pensadas e propostas, mas adquirem diferentes contornos em cada contexto de implementação, como mostram os estudos de Marcia Lunardi (2003), Ramon Alcântara (2011) e Juliana Mesomo (2011). Além disso, as práticas inclusivas cotidianas envolvem relações de poder e governamento (LOPES; HATTGE, 2009), ou seja, ações sobre as condutas dos outros e de si, que podem produzir subjetividades inclusivas (MENEZES, 2011).

No Brasil, em 1988, a Constituição Federal, assim como a LDB, em 1996, passou a determinar que o dever do Estado com a educação seria efetivado mediante a garantia de atendimento educacional especializado aos portadores de deficiência, preferencialmente na rede regular de ensino; dever referendado pelo Ministério da Educação, por meio da Secretaria de Educação Especial (FERRAZ, 2009; MONTEIRO, 2009).

Nosso grupo de pesquisa, em consonância com as referidas diretrizes, incorpora o conceito que "defende a heterogeneidade na classe escolar, como situação provocadora de interações entre crianças com situações pessoais as mais diversas" (BEYER, 2006, p. 73). Em nossa perspectiva, não existem dois grupos de alunos nas salas de aula, mas, sim, 
crianças e jovens com singularidades e necessidades variadas. A Educação Inclusiva desafia-nos na direção da construção de uma escola aberta às diferenças, avançando da abordagem da integração - que previa a adaptação dos alunos à escola - para a da inclusão - que implica a revisão de condutas da instituição para atender tais alunos. É nesse sentido que, a seguir, passamos a discutir os modos como as escolas investigadas estão colocando em ação e aprimorando processos de inclusão.

Em reuniões com as equipes diretivas dessas escolas, foi apontada como problema, em turmas finais do III Ciclo, a chegada de alunos com defasagens de conhecimento e com necessidades especiais - principalmente no que diz respeito à deficiência mental, a transtornos globais de desenvolvimento e à vulnerabilidade social ${ }^{11}$-, o que se configurou como uma novidade. Até então, os alunos que chegavam à etapa final do E. F. tinham condições ditas normais de desenvolvimento intelectual, eram alfabetizados, possuíam domínio, mesmo que mínimo, dos conteúdos programáticos para a etapa. Diante desse panorama, segundo a equipe diretiva, professores com formação em cursos de licenciatura, em áreas específicas de conhecimento, tinham dificuldades de lidar com esses "novos" alunos e em exercer papéis diferentes daqueles para os quais foram formados. Ao mesmo tempo, professores licenciados em Pedagogia, com formação especializada nos anos iniciais, sentiam falta de conhecimentos relativos aos diferentes campos de saber, situação que, por vezes, dificultava o entrosamento necessário entre tais profissionais frente às situações enfrentadas na D.C. Essas circunstâncias geraram profundas implicações no cotidiano das escolas, exigindo novas abordagens para "dar conta" dos processos de ensino-aprendizagem e socialização de tais grupos.

Nessa direção, e em conjunto com as escolas, nossos estudos vêm privilegiando as práticas postas em funcionamento nas ações inclusivas, para mobilizar um pensamento crítico sobre as condições em que elas se constituem, objetivando repensar as ações e criar outras experiências no espaço escolar. Para isso, foram realizados os seguintes movimentos: reuniões com equipes diretivas e com professores dessas turmas; análise documental dos registros produzidos nas escolas; observações em salas de aula e em outros espaços das instituições; e análise de produções textuais desses alunos, tematizando sobre a escola, a sala de aula e o projeto de D.C. Desse modo, ao imergirmos na cultura da escola, procuramos expe- 
rienciar o ali vivenciado, o que permite caracterizar esta pesquisa como um estudo de caso, numa perspectiva etnográfica (GEERTZ, 1989).

A seguir, apresentamos aquilo que "vimos" nas salas de aula, como também discutiremos narrativas de professores e alunos a respeito de alguns efeitos da implementação do Projeto D.C.

\section{(Re)inventar-se como professor na docência compartilhada}

Sob nossa ótica, as práticas pedagógicas de uma escola inclusiva precisam contemplar ações diversificadas, flexíveis e articuladas. Diversificadas no sentido de atentar às necessidades dos alunos, considerando seus saberes e suas singularidades; flexíveis para discutir a atual organização do planejamento pedagógico e propor outras práticas com o objetivo de atender às diferenças; e articuladas para que os professores das áreas e os generalistas ${ }^{12}$, junto com a equipe diretiva, desenvolvam ações integradas, de modo a favorecer as aprendizagens dos alunos, oportunizando momentos em que estes estabeleçam conexões entre os diversos conceitos aprendidos. Essas ações são empreendidas, portanto, como alternativa de viabilização da inclusão, no intuito de operacionalizar práticas que gerem aprendizagens cognitivas e sociais. Assim, este estudo vem trazendo pistas para pensarmos práticas afins às pedagogias diferenciadas ${ }^{13}$. Segundo Perrenoud (2000, p. 73), "praticar uma pedagogia diferenciada é fazer com que, quando necessário, cada aluno seja recolocado ou reorientado para uma atividade fecunda para ele". Ainda segundo esse autor, para alcançar isso, "deve-se compreender o que se passa em sua mente, ou seja, entrar em relação, instaurar um diálogo sobre o saber e a aprendizagem”, pois, para ele:

Um dispositivo de pedagogia diferenciada aumenta a probabilidade de que cada indivíduo ou cada grupo encontre, na hora certa, um interlocutor bastante disponível e competente para assumir a situação e reorientar seu trabalho, se possível visando uma regulação não somente das atividades, mas também dos processos de aprendizagem (PERRENOUD, 2000, p. 73).

Ao observarmos uma das turmas da escola $\mathrm{M}$, direcionamos nosso olhar para o exercício docente nas salas de aula, os procedimentos de planejamento adotados pelas professoras e o uso dos ambientes pela 
turma na escola, em especial, a sala de aula e o laboratório de informática. Ainda, utilizamos registros de uma reunião de apresentação e discussão dos primeiros resultados desta pesquisa junto aos professores. Já na escola G., centramos nossa atenção nos registros das reuniões pedagógicas e das observações em sala de aula. Esses movimentos de pesquisa vivenciados nos permitem sinalizar que, no Projeto D.C., torna-se necessário (re)inventar o exercício da docência, no mínimo, em dois aspectos: no desenvolvimento da ação pedagógica exercida em duplas de docentes nas salas de aula e na forma de escolher e abordar os conteúdos escolares, considerando os processos heterogêneos de aprendizagens dos alunos.

No tocante ao primeiro aspecto, embora o projeto pedagógico para a turma observada na Escola M seja o de D.C., nas observações realizadas nas salas de aula e no laboratório de informática, percebemos que: nem sempre estiveram presentes duas professoras atuando no desenvolvimento das atividades; estas eram realizadas pelos alunos, em geral, individualmente; não foram observados trabalhos em grupo com frequência e, inclusive, na sala de aula, foi adotado um espelho de classe circunstancial - com cada um fixado em seu lugar. Se a docência compartilhada exige ações pedagógicas centradas nas interações para produção de aprendizagens, nos questionamos sobre o uso do "espelho de classe", visto ser esta uma estratégia disciplinar direcionada à fixação, à vigilância e ao controle de cada um para a transmissão de conhecimento (FOUCAULT, 1989). Vale dizer que, a partir das discussões entre o grupo de pesquisa e os professores da escola $\mathrm{M}$, percebemos que o uso do "espelho de classe" tem sido uma estratégia mantida em determinados momentos e retirada de cena, em outros, quando o professor se permite propor outras ações. Sem pretender resolver as dificuldades ou apontar saídas para as práticas inclusivas, tais situações merecem ser tematizadas como possibilidade, talvez, para desnaturalizá-las, para desconstruí-las. Percebemos que nelas emergem "embates" entre as práticas escolares em ação, criadas desde a Modernidade, para adestrar e formatar sujeitos para uma máquina social e um projeto pedagógico que, no mínimo, exige que renunciemos ao saber/poder e ao domínio que incorporamos sobre o outro em nossas formações de educadores. (Re)pensar o já vivido no fazer da docência, em seus domínios epistemológicos, políticos e ético-estéticos, possibilitando uma descolonização do pensamento (GALLO, 2006), pode 
nos permitir deixar tocar e transformar com e pelo outro, em direções desconhecidas - criadas no encontro -, tornando os fazeres docentes experiências criativas a cada circunstância que nos acontece.

Em relação ao modo como as professoras planejam e operacionalizam a proposta pedagógica, em uma situação observada, tornou-se visível que a professora de "área" havia estipulado um programa de trabalho, cabendo à professora "generalista" apenas o acompanhamento e o apoio à proposta da colega, e, aos alunos, desenvolvê-la do mesmo modo. Em um projeto como este, torna-se necessário atentar para as diferenças, sem atribuição de posicionamentos desiguais. Chamou-nos a atenção o lugar de suposto saber da professora de área, enquanto expert no que se refere à manutenção de um padrão de planejamento em que se impõe a homogeneidade.

Merece ser referido que a escola G iniciou o Projeto de D.C. há mais tempo do que a escola $\mathrm{M}$. Em reunião ocorrida no segundo semestre de 2009, entre o grupo de pesquisa e os professores que atuam no III Ciclo da referida escola, foram tratados os impasses encontrados por esses professores na efetivação da D.C. A coordenadora pedagógica da escola, ao comentar sobre como se dá o planejamento entre os professores "generalistas" e os das áreas, declarou que "há muita dificuldade de acertar horários entre eles para pensar em planejamento". Ainda, uma integrante da equipe diretiva referiu que "alguns professores priorizam dividir, pensar junto o planejamento para a sua área com a generalista, outros, não. Existe muito professor que não consegue ajustar o horário, por trabalhar em outras escolas, para esse planejamento em conjunto".

$\mathrm{Na}$ discussão, uma professora que atua em uma disciplina de área contou da sua dificuldade em diversificar suas propostas de trabalho: “eu, que sou da área, a gente apresenta uma proposta para todos. Não consigo imaginar mais de uma proposta. Eu não vejo como fazer isso. Para mim isso é um grande problema". Ao mesmo tempo, a professora "generalista" admite que "nem sempre se reunir é possível; pego o conteúdo e adapto". Podemos dizer que, nessa escola, à semelhança da escola $\mathrm{M}$, às vezes, parece funcionar uma hierarquia entre as professoras. No que se refere à atuação docente na realização de suas propostas pedagógicas, uma professora, ainda nessa reunião, afirmou: "a proposta é a mesma, respeitadas as diferenças. Em uma turma, tem dois alunos que não escrevem, eles participam da parte oral e escrevem com a pedagoga propostas 
diferentes. A inclusão ocorre em ritmos diferentes e vejo alguns progressos, não fico angustiada". Por sua vez, uma professora "generalista" manifesta assim sua preocupação: "a mim incomoda que os ditos incluídos estão ali e não temos o que fazer com eles. É importante que cada um deles saiba [aprenda] a temática da aula". Uma professora de área, em seu depoimento, torna visíveis outras dificuldades diante de um projeto que se propõe inclusivo: "não consigo, o problema é organizar a turma; temos questões sociais graves com as quais não sei lidar; é preciso desamarrar os fios de cada um; como cada um aprende; nunca estudamos sobre casos graves de alunos, temos duas alunas com síndrome de Down e nunca estudamos sobre isso".

Frente a esses impasses narrados pelos professores, entendemos que é preciso pensar sobre as complexidades implicadas na D.C., ou seja: como pensamos e lidamos com as categorias atribuídas aos alunos? Como organizar, junto e nos tempos disponíveis, os conhecimentos escolares para produzir aprendizagens significativas? Como estabelecer a seleção de conhecimentos? Como conhecer efetivamente o que os alunos sentem, já sabem, para propor o aprendizado do que ainda não sabem e precisam saber? E, ainda, como conhecer o que podem aprender no presente momento, em vista de suas peculiaridades? Como transgredir as fronteiras entre as disciplinas, aproximando o convívio entre elas, por meio do diálogo advindo da parceria docente e de suas tensões?

Tais questionamentos nos remetem a pensar que o exercício da D.C. consiste em um permanente processo de desconstrução/reinvenção da identidade docente. A ação de compartilhar traz tensões para ambos os docentes, pois é a exposição mais íntima e detalhada de suas crenças pedagógicas, é o embate entre a proposta planejada para o aluno e a concretização da mesma "a dois", assumindo riscos, realizações e fracassos no coletivo da turma e com cada aluno, individualmente. Nesse contexto, cada um dos professores passa a fazer a desconstrução do seu modo de ser docente para construir outro. Como tem alertado François Dubet (1997, p. 226), "quando se pede a um professor para mudar o seu método, não se pede apenas que ele mude de técnica, pede-se para que ele próprio mude”. Em especial, neste projeto de D.C., a identidade docente se constitui a partir da diferença de certos modelos e padrões de ser professor que a Modernidade preconizava. Compartilhar a docência, ou seja, pensar as propostas pedagógicas e exercê-las em conjunto na sala de aula, 
parece ser uma das formas possíveis de produzir a diferença docente, não exatamente uma "identidade". Luciana Loponte (2005, p. 183) sinaliza que "a partir do olhar do outro posso produzir a diferença em mim mesmo, e com isso me multiplico, me transformo". E como fazer isso? Evidentemente, não há receitas. Entretanto, esse processo de compartilhamento (conflituoso) de decisões, sob nossa compreensão, supõe ser imprescindível nos tempos possíveis: estudar em conjunto; exercitar a investigação da diversidade de formas de conhecer-aprender; identificar os objetivos dos conhecimentos abordados; e, o modo como tais conhecimentos podem ser relacionados com os contextos vividos pelos alunos.

\section{"Vou te contar sobre a minha sala de aula"}

O título desta seção se refere à produção textual solicitada aos alunos das escolas pesquisadas. Ao sugerirmos tal produção, objetivávamos conhecer, por meio das narrativas, significações sobre o modo como os alunos do projeto de D.C. percebiam essa experiência escolar. Vimos, então, a leitura dos textos escritos como uma estratégia que criou condições para entrevermos opiniões, sentimentos, julgamentos, enfim, manifestações ricas sobre os processos humanos vivenciados na sala de aula, decorrentes daquele projeto. Visávamos a entender os alunos como sujeitos históricos/sujeitos da experiência, constituídos por práticas sociais que os marcam em suas existências. Assim, concebemos as narrativas, presentes nos seus textos, como acontecimentos que traziam traços daquilo que os tocou e dos sentidos elaborados em suas experiências escolares, ou seja, aquilo que os afetou, inscreveu seus corpos de modo particular (LARROSA, 2002).

Em relação à produção de um texto, estudos (GERALDI, 1991) vêm apontando uma multiplicidade de discussões sobre a complexidade que a envolve. Tal horizonte de compreensão requer considerar a ação linguística entre sujeitos, que se realiza por meio de textos, falados ou escritos, de forma articulada, como um acontecimento discursivo. Assim sendo, é importante destacar que narrar, neste caso, por escrito e a partir de uma proposta direcionada, em primeira pessoa (Vou te contar sobre a minha sala de aula), pressupõe determinadas escolhas: o que dizer, para quem dizer, de que modo dizer. 
Esse acontecimento discursivo, ou seja, "a montagem do conteúdo" dos textos em questão, concentrou enunciados constituídos de acordo com a visão dos escreventes, mas igualmente atravessados pela imagem dos possíveis interlocutores. Em geral, tais enunciados se apresentaram de forma direta, "espontânea", crítica, mas também com interdições/cortes, silenciamentos refletidos. Um texto organizado para ser lido pelas professoras e pesquisadoras, mesmo seguindo um roteiro prévio "do que dizer" (escreve sobre tua sala, turma, projeto D.C. ...) deixou vir à tona o "mundo real" observado/vivido ou efeitos deste, por meio dos relatos sobre as questões propostas. Yves Reuter (2002, p. 18) explica por que a ação de narrar redescreve o real:

Em primeiro lugar, porque toda palavra ou toda história refere-se ao nosso universo e só pode ser compreendida com referência a ele e às nossas categorias de apreensão do mundo. Em segundo lugar, porque muitas narrativas comuns [...] pretendem ser realistas ou baseadas no real (contam aquilo que realmente teria acontecido). Mas, em todos esses casos, trata-se de efeitos do real, produzidos por meio do texto, mediante diversos procedimentos [...].

Foi a partir dessas perspectivas que nos debruçamos sobre as produções de uma turma da escola M e de duas turmas da escola G. Ao "depurarmos" os textos, logo identificamos os eixos que guiaram a escrita a partir do roteiro indicado pelas professoras: a escola, a sala de aula, a turma, o projeto de D.C. Os alunos autores sentiram-se convidados "a falar" escrevendo. Isso se fez perceber pela extensão presente na maioria dos textos. Pudemos deduzir: tinham o que dizer! Mas, o que disseram?

\section{Sobre a escola e a sala de aula}

Ao contarem sobre suas escolas, salas de aula e demais espaços, os alunos nos falam sobre aspectos relativos à estética e aos cuidados daqueles ambientes: espaços iluminados, amplos e adequados aos trabalhos escolares, não deixando passar incólumes aspectos que poderiam ser repensados, tais como a limpeza das paredes e das cortinas, a manutenção de vidros, lâmpadas, aberturas. Além disso, aparecem peculiaridades; por exemplo, a turma da escola $\mathrm{M}$ deu destaque ao colorido das paredes - pintura feita pelo grupo no ano anterior -, à organização da sala com a pre- 
sença de cartazes elaborados pelos alunos e ao fato de a sala ser próxima ao refeitório. Este local também foi motivo de comentários nos textos da escola G, por ser visto como "enorme", por ter "merenda que lá não tinha" (em outra escola) e, ainda, por ser "especializado para todos os tipos de alunos" (referência aos cadeirantes). Nos textos desses alunos, foi realçada a presença de rampas para "a passagem de alunos que são cadeirantes", que, segundo uma aluna, "foi uma coisa boa que a escola proporcionou não só para alunos que têm deficiência como tetraplegia e, sim, para todos os alunos que têm deficiência física".

Esses elementos do cotidiano escolar trazidos pelos alunos tornam visíveis "detalhes" que os afetam, em seus sentidos - os aromas das comidas, as pinturas/obras criadas por eles, a limpeza, as rampas - e percepções sobre a maneira como os professores se (pre)ocupam com aquele espaço escolar e com as pessoas que ali convivem. Assim, no fazer do dia a dia da escola, para além dos conteúdos escolares, ensinamos, também, por meio dessas outras ações "menores", nem sempre vistas como pedagógicas e sobre as quais, geralmente, não nos dispomos a pensar. Ao nos contarem sobre a escola $G$, os alunos-narradores também nos mostraram saberes incorporados por meio de práticas escolares direcionadas ao acolhimento das diferenças: "a minha escola é para todos e muito especial. É especial porque aceitamos pessoas muito diferentes de outros, e cada um com suas diferenças e dificuldades; a nossa escola funciona mais ou menos assim, ela aceita as diferenças dos alunos, dá mais atenção a quem mais precisa, claro, não deixando os outros de lado; aqui, na escola, não tem diferenças entre os alunos, são todos aceitos sem discriminação". Ao conviverem numa escola que se ocupa com as diferenças, sejam elas cognitivas ou físicas, ou de outra ordem, os alunos trazem, em suas narrativas, modos de pensar e ver "O outro" construídos nas relações escolares.

Outras marcas positivas que atravessaram as narrativas dos alunos da escola $G$ dizem respeito: ao recreio - ampliação do tempo e oferta de atividades; momento propício para conversas, descanso e privacidade dos alunos, presença da música -, às atividades "extraclasse" - os passeios e os vídeos -; e às relações interpessoais afetuosas de alguns professores, as quais acabam por influenciar o gosto dos alunos por algumas disciplinas. Tais situações associadas ao prazer, ao lúdico, à criação, aos afetos foram narradas nesses textos, em geral, em momentos "fora" da sala 
de aula; com práticas educativas que "fogem" aos padrões considerados estritamente pedagógicos; enfim, momentos e práticas escolares que, usualmente, se encontram no "exterior" daquilo que consideramos, tradicionalmente, como pedagógico e como conteúdo (DAYRELL, 2001).

\section{Sobre a turma}

Em se tratando da escola M, os alunos descreveram, convictos, suas relações vistas como harmoniosas, inclusive empregando repetidas vezes a palavra "relacionamento" acompanhada de aspectos positivos. Nas palavras desses alunos: "somos como irmãos; a turma é ótima, alegre, divertida; a turma às vezes é bagunceira, mas, quando quer, há empenho; os colegas são legais; adoro quando estou na sala, pois ela é um lugar que me dá exemplo de vida; relacionamento 100\%". Já os alunos da escola $G$, ao contarem sobre a sua sala de aula, utilizaram, frequentemente, e muitas vezes no início do texto, a expressão "eu gosto de", mostrando, ao mesmo tempo, o critério de apreciação, prazer e afeição pela "minha turma, meus colegas e professores", para, em seguida, narrar situações e motivos associados a tal atribuição e sentimentos, dizendo: "Eu gosto da minha turma porque às vezes a aula é quieta e não é bagunceira, eu gosto dos meus amigos da sala de aula, alguns desde pequenos; eu gosto do meu grupo; eu estou gostando muito dos meus novos colegas". Associadas à manifestação de gostar, especialmente de colegas, estavam presentes as relações de amizade e os momentos de conversa: "Eu vim de outra escola, não conhecia ninguém, veio um cara e comecei a sentar do lado dele, começamos a conversar e ficamos amigos. Eu ainda tô conhecendo a escola, mas, pelo que eu vi até agora, eu gostei; eu gosto de conversar com minhas amigas".

Sandra Fernandes (2008), ao discutir a problemática da amizade em Foucault, salienta que a amizade se desenvolveu como relação social aceita a partir da Antiguidade. Todavia, o filósofo chama nossa atenção para o "esvaziamento" da amizade enquanto relação social a partir do século XVIII, simultaneamente à emergência de práticas direcionadas ao controle da sexualidade e de instituições como o exército, as escolas, as universidades, as burocracias, cujos códigos não admitem relações tão intensas, uma vez que introduzem os afetos onde deveria funcionar a lei 
ou o hábito. Foucault (2004, p. 120) ressalta que "a sociedade e as instituições que constituem sua ossatura limitaram a possibilidade de relações, porque um mundo relacional rico seria extremante complicado de administrar". Pensar a amizade como modo de relação com o outro, que possibilite trocar, afetar e transformar na e pela diferença, exige que pensemos sobre como lidamos, no cotidiano escolar, com aqueles modos de relação que "fogem" ao instituído, como, por exemplo: as conversas - na sala de aula, no pátio, no recreio, tão lembradas pelos alunos -, as quais poderiam criar condições para outras experiências pessoais e interpessoais e outras práticas escolares.

Ainda, relativamente à sociabilidade e à convivência, há momentos sentidos pelos alunos da escola G como "chatos, ruins", que apareceram associados ao desprazer e ao incômodo gerados por comportamentos de colegas vistos como "bagunceiros, brigões, gritões", dando destaque, principalmente, às atitudes dos meninos: "tem dias que as aulas são muito chatas porque alguns meninos bagunçam e estragam tudo"; e também a agitação da turma ao voltar do recreio, a bagunça que impede o trabalho e gera atritos com os professores: "e a professora tentando explicar e ninguém ficava quieto, então teve que vir mais duas professoras".

A esse respeito, os alunos da escola $\mathrm{M}$ também fizeram menção à atitude inadequada de alguns meninos, por arremessarem bolas de papel durante as aulas. Bolinhas de papel arremessadas: ícone popularizado de bagunça, amplamente contestado por esses alunos.

Ao pensarmos os efeitos de práticas pedagógicas não tão homogeneizantes (o professor "ensinando a todos") e individualizantes (cada aluno no seu lugar), instituídas com a finalidade de criar condições de situações de ensino-aprendizagem mais particulares, adquiridas em interações professores-alunos e alunos-alunos, trazemos alguns elementos daquilo que os textos nos contaram sobre como os alunos estavam vendo/sentindo os trabalhos em grupo nas salas de aula. Para os alunos da escola $\mathrm{M}$, esses trabalhos foram considerados como possibilidade de cooperação, de trocas de ideias: "eu aprendi mais em grupo porque a gente compartilha ideias; tem alunos que ajudam os que têm mais dificuldades nos trabalhos". Não se eximiram, porém, de apontar o problema da frequência como obstáculo às aprendizagens. Os alunos da escola $G$, ao nos contarem sobre o trabalho em grupo, dizem: "nós trabalhamos em grupo para os alunos aprenderem mais e ter uma boa convivência com os 
outros; tem grupos de quatro, cinco... para podermos conversar com os outros e poder fazer o trabalho juntos e melhor, nos grupos tem tudo que é tipo de alunos para mostrar que são iguais; fazer grupos; assim é bem melhor, porque quando temos dúvidas e outro sabe, um ajuda o outro". Os momentos vivenciados em grupo - embora invenções escolares que integram o funcionamento do dispositivo escolar de saber/poder, conforme o qual não se aprende/ensina qualquer coisa - parecem trazer situações de ensino-aprendizagens para além dos conteúdos escolarizados, uma vez que os alunos se posicionaram como aprendentes e ensinantes, com as mesmas condições, sem desconsiderar as diferenças e, ainda, as relacionaram com "uma boa convivência". Entretanto, não podemos deixar de referir, também, os alunos que, mesmo em minoria, se manifestaram dizendo gostar daquelas aulas mais quietas "porque nestas aulas ficava cada um no seu lugar", mostrando que, diante de "mesmas" situações, as pessoas têm diversas maneiras de ver e sentir.

\section{Sobre o projeto Docência Compartilhada}

O projeto de D.C. foi visto, pelos alunos da escola M, como um meio que viabiliza aprendizagens. O fato de uma dupla de professoras atender maior número de alunos, durante as atividades, permite que mais atenção seja dispensada àqueles que necessitam esclarecer dúvidas sobre os conteúdos: "eu achei o máximo é ter duas professoras; elas dão mais atenção; aprendi o jeito das professoras explicarem; aprendi coisas que não sabia". Os alunos da escola $G$ mencionaram que os professores "planejam com os alunos para ver o que eles sabem e não sabem; ajudam os alunos mais lentos e os mais rápidos durante a aula, todos conversamos relacionado ao projeto e os trabalhos"; e a aula "é diferente porque alguns alunos que têm problemas se reuniram com nós e então ficou passando a ter duas professoras em nossa turma; a gente consegue entender melhor porque os professores têm mais disposição de ensino com os alunos".

As disciplinas e as professoras responsáveis pelas mesmas também passaram pelo crivo estudantil: Matemática, História, Ciências, Artes, Educação Física e Filosofia (estas últimas, em especial, para a escola $G$ ) foram muito citadas como aulas produtivas, seja em função do modo como os professores se relacionam com os alunos, "o jeito que eles ensi- 
nam e brincam faz prender tua atenção", seja pelo fato de criarem condições para outras abordagens pedagógicas. Mas, em algumas narrativas sobre o funcionamento das aulas, na D.C., apareceram também queixas, em uma das escolas, no que se refere: às metodologias adotadas - "passa matéria no quadro o tempo todo" - e quanto às relações interpessoais que atravessam o modo de ensinar - "não tem nenhuma paciência, explica tudo correndo, fica gritando" - e, também, as situações de bagunça geradoras de "brigas com as professoras". Para pensarmos sobre como os alunos percebem as ações pedagógicas que engendram outras formas de relações, de ensinar/aprender, de pensar/agir no mundo, trazemos o comentário de uma aluna da escola G: "gosto muito daqui, se em todo lugar fosse assim, o nosso mundo poderia se tornar um pouco melhor e que isto que nossos professores ensinam para nós com certeza a gente pode fazer o mesmo, ensinando, ajudando e acolhendo as pessoas, para que o futuro de nossos filhos, quem sabe, seja melhor que o nosso". O saber adquirido por essa aluna, em suas vivências na escola, torna visível a aprendizagem sobre outras formas de convivência e abordagens do conteúdo escolar, que a remetem a pensamentos, simultaneamente, no presente e no futuro.

\section{Considerações finais}

Tendo em vista o objetivo principal de nossa investigação - analisar a implementação do projeto de D.C. em duas escolas cicladas da rede municipal de Porto Alegre/RS -, constatamos, mesmo que em caráter provisório, alguns aspectos a seguir elencados.

A D.C., nos anos finais do Ensino Fundamental, tem sido um permanente desafio de reinvenção da identidade docente. Este seria um primeiro aspecto a ser destacado aqui. Percebemos, também, a paulatina modificação que vem ocorrendo na postura dos chamados professores "especialistas" na condução das aulas, em parceria com os "generalistas", e com os alunos ditos especiais, de forma mais acentuada na escola $G$, que vem desenvolvendo há mais tempo seu projeto. No entanto, o desenvolvimento do trabalho e as relações entre as professoras nem sempre se desencadeiam de forma tranquila. Observamos, muitas vezes, as dificuldades dos docentes em individualizar o ensino e compreender as particula- 
ridades de cada aluno, tendo em vista o procedimento pedagógico, arraigado nas instituições escolares, que contempla propostas homogeneizantes e simultâneas para os grupos.

Para os professores de "área", no início, parecia que a responsabilidade pela aprendizagem dos alunos "especiais" era só do "generalista". Mas, no presente momento, inclusive por demanda dos próprios alunos, que os procuram para solução de suas dúvidas, nem sempre específicas de determinada área de conhecimento, vem acontecendo uma interação maior entre esses professores e seus alunos. Notamos ainda o surgimento de uma aprendizagem coletiva sobre processos de aprendizagem, com a consequente proposição de novas metodologias, que até então não eram desenvolvidas pela estrutura escolar existente.

Um segundo aspecto refere-se ao planejamento conjunto dos professores de tais turmas - "especialistas" e "generalistas" - em termos de seleção de conteúdos e atividades pedagógicas para grupos heterogêneos. Processo este que requer negociação, compatibilização de pontos de vista, visando a organizar propostas diferenciadas para alunos com diferentes níveis de necessidades, mantendo, no entanto, um eixo comum nas propostas. Ainda, buscando não exigir algo além do que cada um pode render em termos de aprendizagem, em cada momento, e fazer avançar tanto quanto possível quem pode avançar.

Um terceiro aspecto a ser destacado diz respeito à desnaturalização das diferenças. Nas salas de aula observadas, em muitas situações, não tem sido possível identificar quem são os alunos especiais inseridos no grupo. Percebemos uma gradativa mudança na relação entre eles, estabelecendo-se uma relação entre iguais, o que não ocorria antes. Também tem se tornado comum alunos ditos normais convidarem alunos especiais para comporem seus grupos de trabalho, por considerarem que eles têm algo a contribuir. Por outro lado, percebemos, às vezes, uma atitude de proteção dos ditos normais com relação aos "incluídos", acentuando uma relação de dependência não desejável.

Uma quarta constatação, no que se refere à forma de enturmação, é de que todos os alunos precisam ser - e estão começando a ser vistos em sua individualidade, prerrogativa não apenas dos ditos anormais. Comentários de professoras no Conselho de Classe, em uma das escolas no final de 2009, vêm corroborar essa afirmação: "há alunos que só trabalham adequadamente em grupos menores e ainda há alunos que 
não têm condições de ficar todo um turno na sala de aula. Para esses precisam ser criadas outras alternativas de atendimento". Tendo como referência o princípio de que, "em termos de avaliação, o aluno é parâmetro de si mesmo", no referido conselho constatamos que a grande maioria dos alunos incluídos avançou em seu desenvolvimento nas áreas avaliadas.

Em síntese, o estudo realizado nos leva a perceber a necessidade de continuarmos discutindo com as escolas temas como: a superação da organização moderna de escola; a defesa do espaço para alfabetização e letramento ao longo do Ensino Fundamental; a inviabilidade da homogeneização de propostas pedagógicas; os critérios existentes de seleção de conteúdos e de atividades pedagógicas; a expectativa de níveis de conhecimentos padronizados para uma mesma turma; as possibilidades reais de aprendizagem dos alunos incluídos, presentes, hoje, nos anos finais do E. F; o papel de educador de adolescentes dos professores daquele nível de ensino, especialistas em uma área de conhecimento e necessitando ampliar seus saberes docentes, no que se refere à formação plena dos seres humanos naquela etapa da vida. E, ainda, manter questionamentos sobre: como organizar propostas pedagógicas que contemplem os conhecimentos e as dúvidas de alunos sobre seu corpo, sua sexualidade, seus desejos e amores adolescentes, diante do saber dos professores? Como ouvir os alunos (e ler seus textos) pode se tornar uma prática escolar cotidiana, e não apenas uma "isca" para depois "dar" os chamados conhecimentos escolares? 


\section{Referências}

ALCÂNTARA, Ramon Luís de Santana. A ordem do discurso na educação especial. 34 REUNIÃO ANUAL DA ANPED. Natal, Anais... 2011. Disponível em: <http://www.anped.org.br/app/webroot/34reuniao/images/trabalhos/GT15/GT15323\%20int.pdf>. Acesso em: 20 mar. 2012.

ARROYO, M. G. Fracasso - sucesso: o peso da cultura escolar e do ordenamento da educação básica. In: ABRAMOWICZ, A.; MOLL, J. (Org.). Para além do fracasso escolar. Campinas: Papirus, 1997. p. 11-26.

ARROYO, M. G. Ciclos de desenvolvimento humano e formação de educadores. Educação e sociedade, Campinas, n. 68, p. 143-162, 1999.

BARRETO, E. S. de S.; MITRULIS, E. Trajetória e desafio dos ciclos escolares no Brasil. In: PERRENOUD, P. Os ciclos de aprendizagem: um caminho para combater o fracasso escolar. Porto Alegre: Artmed, 2004. p. 189-230.

CADERNOS PEDAGÓGICOS 9. Porto Alegre: SMED/POA, 1996; 1999.

FRANCO, C. (Org.) Avaliação, ciclos e promoção na educação. Porto Alegre: Artmed, 2001.

FRANCO, C. Ciclos e letramento na fase inicial do ensino fundamental. $26^{a}$ REUNIÃO DA ANPED. Poços de Caldas: GT 10, Anais... 2003.

FREITAS, L. C. de. Cultura e currículo: uma relação negada na política do sistema de progressão continuada no Estado de São Paulo. Tese (Doutorado) São Paulo, PUC SP, 2000. BATISTA, C. R. A inclusão e seus sentidos: entre edifícios e tendas. In: BATISTA, C., R. (Org.) Inclusão e escolarização - múltiplas perspectivas. Porto Alegre: Mediação, 2006. p. 83-93.

BRASIL, Ministério da Educação. Secretaria de Educação Especial. Política Nacional de Educação Especial na perspectiva da Educação Inclusiva, 2008.

BEYER, H., O. Da integração escolar à educação inclusiva. In: BATISTA, C., R. (Org.) Inclusão e escolarização - múltiplas perspectivas. Porto Alegre: Mediação, 2006. p. 73-81.

DAYRELL, J. A escola como espaço sócio-cultural. In: DAYRELL, J. (Org.) Múltiplos olhares sobre educaşão e cultura. Belo Horizonte: Editora da UFMG, 2001, p. 136-161.

DUBET, F. Quando o sociólogo quer saber o que é ser professor. Revista Brasileira de Educação, São Paulo, n. 5/6, p. 222-231, maio/dez. 1997.

FERNANDES, S. Foucault: a experiência da amizade. In: ALBUQUERQUE JÚNIOR, D. M. de; VEIGA-NETO, A.; SOUZA FILHO, A. Cartografias de Foucault. (Org.). Belo Horizonte: Autêntica, 2008, p. 377-392.

FERRAZ, M. A. F. Rompendo silêncios: alunos com necessidades educativas especiais narram histórias de inclusão. Dissertação (Mestrado em Educação). FACED/UFRGS, 2009. FOUCAULT, M. Vigiar e punir. 29 ed. Petrópolis: Vozes, 1989.

FOUCAULT, M. 1982- O Triunfo social do Prazer Sexual: uma Conversação. In: FOUCAULT, M. Ética, Sexualidade, Política. Rio de Janeiro: Forense, 2004, p. 119-125. (Coleção Ditos e Escritos)

GALLO, S. Foucault: (Re)pensar a Educação. In: RAGO, M.; VEIGA-NETO, A. (Org.) Figuras de Foucault. Belo Horizonte: Autêntica, 2006. p. 253-260.

GEERTZ, C. Estar lá, Escrever Aqui. Diálogo, São Paulo, v. 22, n. 3, p. 58-63, 1989.

GERALDI, J. W. Portos de passagem. São Paulo: Martins Fontes, 1991.

LARROSA, J.. Notas sobre a experiência e o saber da experiência. Revista Brasileira de 
Educação. n. 19, p. 20-28, jan./fev./mar./abr. 2002.

LOPES, Maura Corcini; HATTGE, Morgana Domênica (Orgs.) Inclusão Escolar. conjunto de práticas que governam. Belo Horizonte: Autêntica, 2009.

LOPONTE, L. G. Docência artista: arte, estética de si e subjetividades femininas. Tese (Doutorado em Educação), Porto Alegre, PPGEDU/FACED/UFRGS, 2005.

LUNARDI, Marcia Lise. A produção da anormalidade surda nos discursos da Educação Especial. Tese (Doutorado em Educação), Porto Alegre, PPGEDU/FACED/UFRGS, 2003.

MENEZES, Eliana da C. Pereira de. A maquinaria escolar na produção de subjetividades para uma sociedade inclusiva. Tese (Doutorado em Educação), São Leopoldo-RS, PPGEDU/UNISINOS, 2011.

MESOMO, Juliana Feronatto. Sentidos da Inclusão Escolar em uma escola da rede municipal de Porto Alegre-RS. Trabalho de Conclusão de Curso (Licenciatura em Pedagogia), Porto Alegre, UFRGS, 2011.

MONTEIRO, M. R. C. Todos os alunos podem aprender: a inclusão de alunos com deficiências no III Ciclo. Projeto de dissertação de mestrado apresentada ao PPGEDU da FACED/UFRGS, 2009.

PERRENOUD, P. Profissionalização do professor e desenvolvimento de ciclos de aprendizagem. Cadernos de Pesquisa, São Paulo, n. 108, p. 7-26, nov. 1999.

PERRENOUD, P. Pedagogia diferenciada: das intenções à ação. Porto Alegre: Artmed, 2000.

PERRENOUD, P. Os ciclos de aprendizagem: um caminho para combater o fracasso escolar. Porto Alegre: Artmed, 2004.

REUTER, Y. A análise da narrativa: o texto, a ficção e a narração. Rio de Janeiro: Difel, 2002.

SMED - SECRETARIA MUNICIPAL DE EDUCAÇÃO DE PORTO ALEGRE. Cadernos Pedagógicos. 2ed., n. 9, Porto Alegre: SMED, 1999.

VASQUES, Carla Karnoppi. Transtornos globais do desenvolvimento e educação: análise da produção científico-acadêmica. 31 a REUNIÃO DA ANPED. Caxambu-MG, Anais..., 2008. Disponível em

$<$ http://www.anped.org.br/reunioes/31ra/1trabalho/GT15-4469-Int.pdf>. Acesso em: 26 mar. 2012.

XAVIER, M. L. M. A escola cidadã estruturada por ciclos de formação - reflexões sobre o projeto educacional do município de Porto Alegre de 1989 a 2004. In: KRUG, Andrea R. F. (Org.). Ciclos em Revista. Rio de Janeiro: Wak, 2007. p. 52-67. 


\section{Notas}

1 Os autores assumem a responsabilidade pelo conteúdo do presente trabalho e pelas ideias nele expressas.

2 Instituição financiadora do projeto de pesquisa: Propesq, Fapergs, CNPq. 3 Grupo constituído desde 1992, sediado em uma universidade federal do Sul do país. 4 “Aluno", aqui, está sendo entendido como uma categoria culturalmente construída.

5 Modalidade de gestão do orçamento municipal instituído pelo Partido dos Trabalhadores, responsável, então, pela administração da cidade de Porto Alegre.

6 A escola - E. M. Monte Cristo - foi autorizada no Orçamento Participativo de 1992. A obra foi realizada no período de 1993 a 1995.

7 Sua experiência serviu de referência para as demais escolas da rede, que, paulatinamente, foram adotando organização semelhante.

8 Ver Caderno Pedagógico n. 9, p. 59-64, 1996.

9 O termo NEE aparece em documentos do Ministério da Educação no Brasil, já em 1994, por influência da Declaração de Salamanca, e refere-se a todas crianças ou jovens cujas necessidades se originam em função de deficiências ou dificuldades de aprendizagem.

10 Segundo Baptista (2006), na Itália, há projetos de organização escolar defendendo a pluridocência desde os primeiros anos do E. F.

11 Esta forma de as escolas nomearem os alunos fundamenta-se em diagnósticos emitidos por médicos e nas percepções da escola e das famílias. Os alunos considerados pelas escolas em situação de vulnerabilidade social são aqueles cujas moradias localizam-se em zonas de tráfico de drogas, que permanecem longas horas na rua e vivem em situação econômica precária.

12 A denominação "generalista" é adotada pela escola. Cabe à professora generalista, segundo a escola, acompanhar os professores das áreas e, ainda, acompanhar os alunos com dificuldades de aprendizagem, principalmente na alfabetização.

13 Sabemos que Perrenoud não se afilia à perspectiva teórica assumida neste artigo, entretanto, são possíveis algumas aproximações, em especial quando se trata da proposição de práticas curriculares a serem desenvolvidas nas salas de aula com alunos incluídos por professores que compartilham a docência. 
Recebido: 18/02/2011

Aprovado: 14/05/2012

Contato:

Universidade Federal do Rio Grande do Sul

Faculdade de Educação

Departamento de Ensino e Currículo

Avenida Paulo Gama, s/n

prédio 12201, sala 908

CEP 90350-070

Porto Alegre, RS

Brasil

Educação em Revista | Belo Horizonte | v.28 | n.02 | p.285-308 | jun. 2012 